\title{
The use of human resources literature regarding the relationship between affect and student academic performance
}

\author{
Authors: \\ Chris W. Callaghan ${ }^{1}$ \\ Elmarie Papageorgiou ${ }^{2}$ \\ Affiliations: \\ ${ }^{1}$ School of Economic and \\ Business Sciences, University \\ of the Witwatersrand, \\ South Africa \\ ${ }^{2}$ School of Accountancy, \\ University of the \\ Witwatersrand, South Africa \\ Correspondence to: \\ Chris Callaghan \\ Email: \\ chris.callaghan@wits.ac.za \\ Postal address: \\ Private Bag X3, University \\ of the Witwatersrand 2050, \\ South Africa \\ Dates: \\ Received: 17 Dec. 2013 \\ Accepted: 24 May 2014 \\ Published: 06 Nov. 2014 \\ How to cite this article: \\ Callaghan, C.W., \& \\ Papageorgiou, E. (2014). \\ The use of human resources \\ literature regarding the \\ relationship between affect \\ and student academic \\ performance. SA Journal \\ of Human Resource \\ Management/SA Tydskrif vir \\ Menslikehulpbronbestuur, \\ 12(1) Art. \#617, 11 pages. \\ http://dx.doi.org/10.4102/ \\ sajhrm.v12i1.617 \\ Copyright: \\ (C) 2014. The Authors. \\ Licensee: AOSIS \\ OpenJournals. This work \\ is licensed under the \\ Creative Commons \\ Attribution License.
}

Orientation: In human resources literature affect, or affectivity, has been identified as contributing, either negatively or positively, to different forms of performance in a range of different contexts.

Research purpose: The aim of the study was to empirically test theory that predicts that affect can influence performance; in this case the academic performance of students in the South African higher education context.

Motivation for the study: Human resources job performance theory seems to offer important insights when extended into other contexts of individual performance. The specific potential influence of affect on student performance is unclear in this context.

Research design, approach and method: A non-probability comprehensive sample of all students registered for first-year accountancy $(n=719)$ was used. Confirmatory factor analysis, exploratory factor analysis and bivariate tests of association were used to empirically test theory predicting relationships between affect and student academic performance.

Main findings: In general the findings support the predications derived from affect theory, that negative affect is negatively associated with student performance and that positive affect is positively associated with student performance. Yet, the results suggest that affect might not, in this context, reflect the two-dimensional theoretical structure. In particular, negative affectivity might better be considered as a three-dimensioned construct.

Practical/managerial implications: These results suggest that proactive measures may need to be taken by higher education institutions to support first-year students affectively. Student advisors or counsellors should be appointed, with a specific focus on providing support for student anxiety and other contextual frustrations to which individuals with higher levels of negative affect might be particularly vulnerable.

Contribution: These findings provide new insights into the importance of extending human resource theory into different contexts. Knowledge of the specific potential constraints posed by affect to student performance is provided.

\section{Introduction}

Over time, a dominant tension in the affect literature is reflected in the arguments of certain theorists (Brief, Burke, George, Robinson \& Webster, 1988; Podsakoff, MacKenzie, Lee \& Podsakoff, 2003) who have argued that negative affect poses a methodological threat in research as a 'nuisance' variable (through an indirect influence), and the arguments of Spektor, Zapf, Chen and Frese (2000), who argue that affect has a substantive influence and should be treated as an important causal variable in its own right (with a direct influence).

From the literature, the potential influence of affect within the context of first-year accounting students is limited. It is argued in this research that negative and positive affect have a direct and substantive influence on the performance of first-year students in this context. This article seeks to contribute to the human resources literature by offering insight into these relationships. In doing so, implications for theory and practice are derived. Recommendations are made for how to support and empower students and their academic performance.

Affect, or affectivity, represents a mood or emotional, dispositional orientation that reflects substantive, or theoretically predicted, individual differences (Luo \& Bao, 2013). Affect is comprised of two separate dimensions: negative affect (NA) and positive affect (PA) (Luo \& Bao, 2013). NA is a: 
general dimension of subjective distress and unpleasurable engagement that subsumes a variety of aversive mood states, including anger, contempt, disgust, guilt, fear and nervousness, with low NA being a state of calmness and serenity. (Watson, Clark \& Tellegen, 1988, p. 1063).

PA 'reflects the extent to which a person feels enthusiastic, active and alert'; high PA is associated with 'a state of high energy, full concentration, and pleasurable engagement, whereas low PA is characterised by sadness and lethargy' (Watson et al., 1988, p. 1063).

Over time, however, what is absent from the affect literature is the nature of its potential influence, as a substantive effect, on student performance. More specifically, there seems to be no previous research on the potential influence of affect on student performance in the South African higher education context.

NA has been found to potentially constrain different dimensions of performance through a range of different effects, for example through its negative influence on creativity at a point in time (Bledow, Rosing \& Frese, 2013), its constraint to proactive responses to challenges (Parker, Johnson, Collins \& Nguyen, 2013) and its association with higher turnover likelihood (Vandenberghe, Panaccio \& Ayed, 2011) and workplace deviance (Chen, Chen \& Liu, 2013).

The influence of affect on performance, however, is not immutable. In experimental conditions, PA has also been shown to increase, and NA to decrease, when tasks are more meaningful (Schutte, Searle, Meade \& Dark, 2012). According to Bledow et al. (2013), creativity, or the development of new and useful ideas, in students can be increased through the management of their affectivity, through the facilitation of positive affect. According to these perspectives, affect can be managed. Knowledge of the specific dimensions of affect that are associated with student performance may make it easier to support and empower students in this context.

High NA individuals typically focus more on negative aspects of themselves and circumstances, accentuating the negative, and are more likely to experience distress (Watson \& Clark, 1984). High PA individuals typically reflect characteristics opposite to these, but low NA does not necessarily correspond with PA; these are separate constructs (Watson \& Clark, 1984). Although our understanding of the influence of affect on a range of different work performance outcomes has improved over time, questions still remain as to the role of affect in other domains of performance. One particular performance domain that seems to not have received sufficient attention to date is that of student performance. The purpose of this study is to address this gap in the literature.

According to the World Economic Forum's (2012) global competitiveness report, South Africa currently has the fifth lowest-rated education system in the world. It is possible that appropriate research can provide insight to improve educational outcomes in this context. This research seeks to argue that support given to tertiary-level students should also take the form of affectivity support. Empirical evidence is presented in this article in support of this argument and recommendations are derived from these findings.

\section{Purpose}

The objective of this research is to test theory that relates affect to student academic performance. The research question posed in this study is: To what extent does affect potentially constrain, or enable, student academic performance? It is argued that this investigation can make a significant contribution to the literature by identifying the potential influence of certain affective states on student performance, in a context in which improved performance can ultimately result in fundamentally improved employment prospects and other positive externalities for individual students.

This study therefore undertakes a confirmatory factor analysis (CFA) of the measurement model structure of affect in this context, followed by a test of the structural model of the relationships between individual affect items, together with the latent variables positive and negative affect, and student academic performance.

Bivariate analysis and exploratory factor analysis (EFA) are also employed in order to test theory that relates affect to student performance. On the basis of the results, implications are highlighted and recommendations are made.

This article is structured as follows. Firstly, the theoretical framework of the study is introduced, drawing on theory that relates to the influence of affectivity in the job performance literature. Then, the methodology applied in the research is discussed. After this, the results of the study are discussed and implications for theory and for practice are derived. The article concludes with a summary of the findings and recommendations for further research.

\section{Literature review}

\section{The structure of affect}

As discussed above, affect represents a mood or emotional, dispositional orientation that is theoretically comprised of two separate dimensions: negative and positive affect (Watson \& Clark, 1984). As already defined, NA 'subsumes a variety of aversive mood states, including anger, contempt, disgust, guilt, fear and nervousness' and low NA is associated with 'a state of calmness and serenity' (Watson et al., 1988, p. 1063). This dimension is considered substantively different from PA, which, as already discussed, is associated with 'a state of high energy, full concentration, and pleasurable engagement, whereas low PA is characterised by sadness and lethargy' (Watson et al., 1988, p. 1063).

A thorough analysis of the relationships around affect first requires this theoretical prediction (that affect is comprised of two dimensions) to be verified in this context. PA has been found to comprise different component categories. Research 
by Lowe and Reckers (2012) found PA to load on two factors that accounted for $61.35 \%$ of the variance in their analysis: a factor termed 'Enthusiastic/Aroused' and another factor categorised as 'Happiness' (comprised of the variables happy, pleased, optimistic and content) (Lowe \& Reckers, 2012).

However, other studies in different contexts support a two-factor model comprising NA and PA as component categories (Crawford \& Henry, 2004; Ebesutani, Okamura, Higa-McMillan \& Chorpita, 2011; Lonigan, Hooe, David \& Kistner, 1999). The theoretical prediction that affect presents as a two-dimensional structure (Watson et al., 1988) in this context is therefore tested; hence, the testing of Hypothesis 1: that affect represents a two-factor structure.

\section{Affect as a substantive versus a nuisance variable}

As also indicated in the previous section, a dominant tension in the affect literature exists between (1) the arguments of Brief et al. (1988) and Podsakoff et al. (2003), who argue that negative affect poses a methodological threat to associations as a 'nuisance' variable (and should routinely be partialled out, particularly in stress-related research) and (2) the arguments of Spektor et al. (2000), who argue that affect has a substantive influence, should be treated as an important causal variable in its own right and should not be controlled for.

For Brief et al. (1988), NA can obscure tested relationships between other variables. Examples of such obscured relationships are the zero-order relationships between job stress and job strain and between job stress and somatic complaints at work, which reduce in significance when NA is controlled for using partial correlation analysis (Brief et al., 1988). Other research has also supported the potential role of NA in measurement contamination of substantive variables (Williams, Gavin \& Williams, 1996). Brief et al. (1988, p. 196) argue further that other forms of stress-related associations might also be 'contaminated' by NA, which should therefore not be ignored as an underlying methodological nuisance factor.

However, for Spektor et al. (2000, p. 79), if NA 'has a substantive role, one should not partial it as this can lead to removing the effects of the very variables one wishes to study'. Other research also supports a substantive role for NA, rather than a confounding or nuisance role (Moyle, 1995). Spektor et al. (2000) argue that NA can directly influence intrinsic relationships through six causal mechanisms:

- The perception mechanism, which relates to the tendency of high NA individuals to perceive phenomena in a negtive way.

- The hyper-responsivity mechanism, which relates to the tendency of high NA individuals to respond to stimuli more intensely than others do (an effect which has been found to have a causal negative influence on job satisfaction).

- The selection mechanism, related to the relatively higher presence of high NA individuals in jobs with lower autonomy and job scope, which might reflect their relatively poorer performance in job selection interviews found in certain laboratory studies.
- The stressor creation mechanism, related to the propensity of high NA people to, through their behaviour, create job stress for themselves, often through conflicts with others or through relatively lower levels of work performance. (According to the literature, neurotic or depressive behaviours also typically elicit negative reactions from others.)

- The mood mechanism, in which the transitive mood component of affect (which has been found in some cases to have a larger influence than the stable component) can influence relationships between intrinsic variables in a stronger way than the trait of NA itself, although job conditions themselves can also influence mood and, indeed, also influence NA itself. (Hence, mood should also not be treated as a nuisance variable but rather as a substantive influence.)

- The causality mechanism, which relates to the potential influence of job circumstances and context upon NA itself, particularly the influence of job satisfaction on NA; individuals that are dissatisfied with their jobs are typically more likely to become higher in NA.

Spektor et al. (2000) therefore stress that the role of NA is typically substantive and that partialling, or controlling for the influence, of variables should not be undertaken purely on the rationale that that 'nuisance' variables need to be controlled for; it cannot be assumed that correlations between work variables are inflated by an NA bias. Other research offers examples where NA is found to have a substantive influence in tested relationships rather than to be a nuisance variable (Bledow et al., 2013; George \& Zhou, 2002; Storbeck, 2013).

Such partialling 'is a dangerous procedure because of the potential to remove substantive effects rather than bias'; partialling can be used, but not purely 'for the purpose of controlling nuisance variance', because a variable first needs to be conclusively demonstrated to be a bias variable, and only a bias variable, before it qualifies for this treatment (Spektor et al., 2000, p. 90).

In other words, a bias variable would need to be related to different variables and also would need to be shown to not have substantive effects before it would warrant this treatment (Spektor et al., 2000). It is, however, possible for NA to act as a bias variable, but it has also been shown to have substantive effects and therefore should not typically be assumed to be a nuisance variable (Spektor et al., 2000).

What, then, are the conditions under which affect might potentially act as a bias variable? When theoretical overlap exists between certain variables and affect, or where construct measures comprise an affective tone, the potential biasing effect of NA might be more likely to exist (Spektor et al., 2000).

\section{Affect and potential student performance}

In other literature, affect has recently been studied in relation to its potential influence on a range of different and diverse 
intrinsic job-related relationships, for example its influence on creativity in student populations (Bledow et al., 2013), the mechanisms by which it typically decreases with age (Shallcross, Ford, Floerke \& Mauss, 2013), its influence related to ethical behaviours (Lowe \& Reckers, 2012) and other research that is considered below.

A tension, however, is also present in the affect literature as to its precise influence on performance. On the one hand, negative affect has been found to be positively associated with supervisor ratings of creativity, as long as it is present together with positive affect within a supportive context (Bledow et al., 2013). Similarly, NA in the form of mood has also been found to be positively related to creative performance when 'perceived recognition and rewards for creative performance and clarity of feelings' are high, perhaps because NA elicits effort and counteracts the influence of complacency (George \& Zhou, 2002). On the other hand, most studies typically report negative or no relationships between negative affect and creativity; at any point in time it inhibits creativity (Bledow et al., 2013). Positive affectivity has been found to be positively and linearly related to creativity in organisations (Amabile, Barsade, Mueller \& Staw, 2005). However, positive affectivity in the form of mood has also been found to be negatively related to creative performance when higher perceived recognition and rewards for creativity and clarity of feelings are present, possibly due to complacency effects (George \& Zhou, 2002). In certain instances, unethical behaviours have been found to potentially trigger PA (Ruedy, Moore, Gino \& Schweitzer, 2013).

Bledow et al. (2013) argue that changes from negative affective states to positive affective states are causally related to increases in creativity. A positive characteristic of NA is that it can provide a focus on challenges and on the investment of effort required to address these (Bledow et al., 2013).

Other research, however, presents a negative perspective of the relationships between NA and job performance. NA has been found to moderate the effect of job designed support on task performance (Parker et al., 2013). Individuals higher in NA have been found to react more strongly to stressors (O’Brien, Terry \& Jimmieson, 2008). NA has also been found to be associated with an increased likelihood of employee aggression towards customers (Wegge, Van Dick \& Von Bernstorff, 2010). Individuals with higher NA are found to use structural support to protect themselves from resource loss, whereas those with higher positive affect are found to 'accumulate further resources by expanding their skill utilisation and/or by engaging in proactive work behaviour' (Parker et al., 2013, p. 870). According to their findings, Parker et al. (2013) argue that individuals with high NA are typically more concerned with protecting themselves than with accumulating new resources in work situations.

Individuals in negative and positive affective states have also been found to encode memories in different ways (Storbeck, 2013). Affect also has psychophysiological dimensions: relief from pain has been found to reduce negative affect and stimulate positive affect (Franklin, Lee, Hanna \& Prinstein, 2013). Negative affectivity has also been shown to potentially increase the intensity of job stress and job strain in work contexts (Brief et al., 1988).

NA has been found to be related to two dominant motivational systems in individuals. Research indicates that NA typically mediates the relationships between reward responsiveness and gambling severity (Atkinson, Sharp, Schmitz \& Yaroslavsky, 2013). Atkinson et al. (2013) tested reinforcement sensitivity theory, which predicts that two motivational systems drive the emotional responses of individuals: the appetitive or approach system associated with behaviour activated towards rewards (behavioural activation system [BAS]) and the defensive or withdrawal system approach (behavioural inhibition system [BIS]), associated with the inhibition of behaviour associated with punishment. BIS is found to typically be associated with negative affect and BAS is found to be inversely associated with negative affect (Atkinson et al., 2013). Given differences between individuals in the extent to which either of these motivational systems proposed by Atkinson et al. (2013) is present in an individual, students with BAS motivations might be expected to perform better because of their higher levels of proactiveness. NA might be expected to constrain student performance according to this dimension.

Affect can also have an influence on decision-making. Decision-making does not typically occur using cognition alone; affect is inextricably involved (Lowe \& Reckers, 2012). The literature typically differentiates between two components of affect on the basis of their duration: emotions, which are typically considered to be short term, and mood, which is associated with the longer term (Lowe \& Reckers, 2012). A further differentiation offered by the literature is that mood states lack the 'trigger' or 'triggering event' that emotions have (Lowe \& Reckers, 2012).

In work contexts, high NA individuals with different job continuance commitment profiles have been found to have higher turnover likelihood (Vandenberghe et al., 2011). Co-incidence of high NA and high social inhibition in an individual has been found to be associated with a condition, termed Type D personality, which can be related to heart disease (Denollet, 2005).

Affect has, however, also been shown to be amenable to efforts to manage it. In experimental conditions, PA has been shown to increase, and NA to decrease, when tasks are more meaningful (Schutte et al., 2012). Similarly, increases in job satisfaction have been found to influence affect. Relationships between affect (NA and PA) and both job performance and turnover have been found to be moderated by the influence of job satisfaction (Bouckenooghe, Raja \& Butt, 2013). High NA employees have been found to be significantly more likely to reciprocate customer incivility across contexts (Walker, Van Jaarsveld \& Skarlicki, 2014). NA has been found to be 
positively associated with workplace deviance (Chen et al., 2013). However, the rules climate, or the strength of a regime of rules in an organisation, has also been found to moderate and reduce the relationship between NA and workplace deviance (Chen et al., 2013).

PA has been found to influence behaviour, with a range of different effects. Examples of these effects are seen in findings that suggest that PA can act as a moderator of transformational leadership (Gilmore, Hu, Wei, Tetrick \& Zaccaro, 2013), that it can influence beliefs, such as those related to procedural justice (Lucas, 2009), that it can mediate citizenship behaviour (Jain, Malhotra \& Guan, 2012) and that it is strongly associated with global job satisfaction (Bowling, Hendricks \& Wagner, 2008). PA has also been found to be negatively associated with emotional dissonance (Wegge et al., 2010). However, the primary motivational mechanism associated with PA that predicts a positive association between PA and student performance seems to be the BAS motivational system (Atkinson et al., 2013), although this mechanism primarily relates to the extent to which PA and NA are related: the common portion, or shared variance between them.

According to Bledow et al. (2013), creativity, or the development of new and useful ideas, in students can be increased through the management of their affectivity, through the facilitation of PA. In contrast, George and Zhou (2002) have argued that PA can lead to complacency and lower levels of creative performance. Nevertheless, before the management of affect can be considered, knowledge is needed as to what its potential influence is.

This article therefore seeks to identify the potential influence of affect on student performance. Despite the different causal mechanisms that the literature suggests might account for a positive relationship between PA and student performance, the identification of a dominant causal mechanism from these findings is beyond the scope of this research. This research seeks only to specifically test this body of theory which, on the whole, predicts a positive relationship between PA and student performance and a negative relationship between NA and student performance.

\section{Method}

The study used a cross-sectional associative research design. The research locates itself within the postpositivist paradigm (Cresswell, 2003). Ontologically and epistemologically, this paradigm recognises objective relationships between phenomena and an objective reality that underlies these relationships (Cresswell, 2003). Theory was therefore derived from the literature for empirical testing.

\section{Measures}

The general Positive and Negative Affect Schedule (PANAS) scales developed by Watson et al. (1988) were used. Previous research findings indicate that these scales have high internal consistency and are stable over time (Crawford \& Henry, 2004; Watson et al., 1988). Test-retest reliability for these scales is also high; the 'stability coefficients of the general ratings are high enough to suggest that they may in fact be used as trait measures of affect' (Watson et al., 1988, p. 1065). This scale remains a staple of contemporary affect research (Bledow et al., 2013; Lowe \& Reckers, 2012). Negative affect was therefore measured using the following ten items: upset, guilty, hostile, ashamed, distressed, afraid, irritable, nervous, jittery and scared; positive affect was measured by the following ten items: interested, excited, mentally strong, enthusiastic, alert, inspired, determined, attentive, active and proud (Watson et al., 1988).

\section{Participants}

The sampling frame of this study included all students registered for the first-year accounting programme at a large South African university. The university is a researchoriented university. A purposive comprehensive sampling process was applied. Despite a few refusals and incomplete submissions, a response rate of $91 \%(n=719)$ was achieved from the total number of students sampled (790).

Ethics clearance was obtained from the university's ethics committee. The unit of analysis was the individual. Anonymity and confidentiality were assured, in that results were only reported at the grouped level of analysis, not at the individual level.

Most of the sample was African (65\%). White students made up $14 \%$ of the sample. Asian students comprised $12 \%$ and students of mixed race comprised $3 \%$ of the sample. About $5 \%$ of students classified themselves as 'other'. About $91 \%$ of the respondents reported being born in South Africa.

\section{Analysis}

The data were analysed using SPSS 20, and its structural equation modelling (SEM) programme, AMOS. CFA was used to test the factoral structure of the PANAS scales. A structural model was then tested. Post hoc tests were then applied in order to suggest a model specific to this context that offered an improved fit to the data. Bivariate tests were also conducted in order to provide further insight into bivariate relationships. Bootstrapping was used in order to check the confidence levels of the findings.

\section{Results and discussion}

In this section, the univariate findings are first reported and discussed. Bivariate and multivariate results are then reported and discussed.

\section{Univariate findings}

The univariate statistics for the affect items are reported in Table 1. The mean value for student marks is $55.34 \%$, with a standard deviation of 14.6, a skewness value of -0.574 and a kurtosis measure of 0.026 . The highest responses 
were obtained for the determined variable, followed by the mentally strong item. The lowest responses related to ashamed, followed by the guilty item. In order to improve the normality of the distribution of the affect variables, transformation of certain of the variables was applied. The univariate statistics of these items are shown in Table 1. Variables with a negative skew were transposed prior to transformations. Items with skewness of between 0.8 and 1.5 were transformed using square root transformations (one item was transformed in this category: upset). Items with skewness of between 1.0 and 2.0 were transformed using natural $\log$ transformations (transformed variables in this category included the following: guilty, hostile, ashamed and determined). Items with skewness of between 3.0 and 4.0 were earmarked for transformation using an inverse function but none was found with this level of skewness. Once these transformations were performed, the levels of skewness were found to be substantially reduced. These variables were then used for the CFA process, the results of which are diagrammatically represented in Figure 1.

\section{Bivariate and multivariate findings \\ Hypothesis 1: Affect represents a two-factor structure}

The PANAS (Watson et al., 1988) model hypothesises that responses can be explained by two factors: negative affectivity and positive affectivity. The measurement model for the PANAS scales was therefore tested. This hypothesis was tested in order to understand if this model was a valid fit with data from this context.

The model (Figure 1) has 230 distinct sample moments, 61 distinct parameters to be estimated and 169 degrees of freedom $(n=719)$. The minimum was achieved, with a chi-squared value of 1024.757 ( $p<0.0001)$. Although the coefficient values might be difficult to read, the decision was made to show them on this diagram.

TABLE 1: Univariate statistics for the affect items.

\begin{tabular}{lllll}
\hline Affect items & Mean & Median & Skewness & Kurtosis \\
\hline Distressed & 2.664 & 3.0 & 0.193 & -0.722 \\
Excited & 3.591 & 4.0 & -0.479 & -0.181 \\
Upset & 1.976 & 2.0 & 0.988 & 0.174 \\
Mentally strong & 3.898 & 4.0 & -0.641 & 0.186 \\
Guilty & 1.77 & 1.0 & 1.356 & 0.890 \\
Scared & 2.435 & 2.0 & 0.596 & -0.775 \\
Hostile & 1.820 & 1.0 & 1.128 & 0.441 \\
Enthusiastic & 3.677 & 4.0 & -0.508 & -0.167 \\
Proud & 3.7 & 4.0 & -0.599 & -0.344 \\
Irritable & 2.37 & 2.0 & 0.549 & -0.667 \\
Alert & 3.624 & 4.0 & -0.350 & -0.284 \\
Ashamed & 1.634 & 1.0 & 1.739 & 2.224 \\
Inspired & 3.959 & 4.0 & -0.771 & -0.146 \\
Nervous & 2.82 & 3.0 & 0.175 & -0.988 \\
Determined & 4.233 & 4.0 & -1.017 & 0.798 \\
Attentive & 3.713 & 4.0 & -0.423 & -0.178 \\
Jittery & 2.103 & 2.0 & 0.629 & -0.478 \\
Active & 3.693 & 4.0 & -0.436 & -0.346 \\
Afraid & 2.19 & 2.0 & 0.907 & -0.235 \\
\hline
\end{tabular}

As an absolute fit index, the Root Mean Square Error of Approximation (RMSEA) value (0.084) is just over the cutoff value of 0.05 or 0.08. Hair, Black, Babin and Anderson (2010, p. 667) stress that although 'previous research had sometimes pointed to a cutoff value of 0.05 or 0.08 , more recent research points to the fact that drawing an absolute cutoff for RMSEA is inadvisable'.

The comparative fit index (CFI) value was 0.859 , which was just short of the 0.9 value, indicating a good model fit (Hair et al., 2010). The Tucker-Lewis value for the model (0.825) and the normed fit index value (0.837) also indicate that the model's fit is just short of what is typically regarded as a good fit. Similarly, the parsimony normed fit index of the model is 0.673 , also indicating that the fit of the model might be less than adequate. Further, Hoelter's statistic for the model is 141 (at 0.05) and 151 (at 0.01), further suggesting that the model might not adequately reflect the sample data (Byrne, 2010).

The hypothesis was therefore not taken to be supported on the basis of these tests. These results are interpreted to contest the findings of Watson et al. (1988) that these scales form a two-factor structure, at least in this context. Further paths between PA and NA measures were suggested by the modification indices (MI) statistics, which were taken to contest the theoretical structure of affect as two-dimensional in this context. It is possible that affectivity in this context might be better represented by a second-order structure. Further investigation into the factor structure of affectivity and the way in which the data matched the theory in this context was therefore undertaken.

\section{Hypothesis 2: Affect is significantly associated with student performance}

In order to test this hypothesis, different tests were applied. Firstly, a structural equation model was tested, comprising both measurement and structural components, with student marks as the dependent variable measure of student performance. This multivariate test of the relationships was expected to take into account the entire model of associations. Next, an EFA was undertaken. Bivariate tests were then performed on the relationships between each of the individual observed affect items and student performance. The results were then discussed holistically.

The structural equation model, shown in Figure 2, has a chisquared value of $1105.362(p<0.0001 ; d f=188 ; \mathrm{CFI}=0.850$; RMEA $=0.082$; Expected Cross-Validation Index [ECVI] $=1.659)$. Model fit issues were found to be present. The bootstrapped regression weight from negative affectivity to student performance $(\beta=-12.126$; confidence interval $[\mathrm{CI}]=-19.333[1] ;-5.137[\mathrm{u}])$ was significant $(p<0.004)$. However, the regression weight from positive affectivity to student performance was not $(\beta=1.346$; $C I=-0.409$ [1]; $3.0001[\mathrm{u}] ; p<0.206)$. The standardised equivalent statistics $(\beta)$ for these two paths were $-0.111(\mathrm{CI}=-0.169[1] ;-0.047[\mathrm{~h}]$; $p<0.005)$ for NA and $0.055(\mathrm{CI}=-0.016[1] ; 0.125[\mathrm{u}] ; p<0.203)$ for PA. The bootstrapping tests utilised 5000 iterations. 


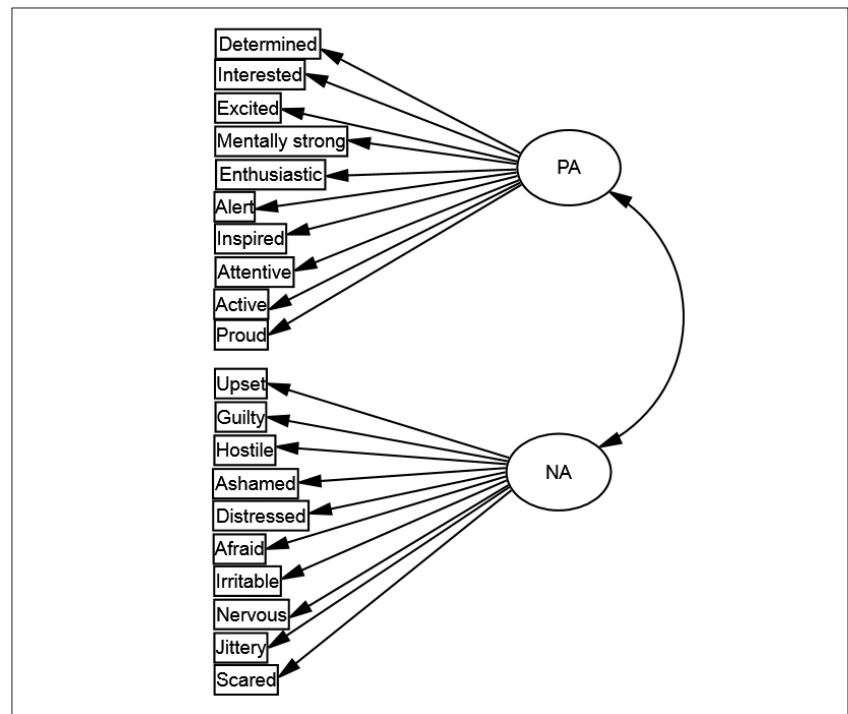

Source: Authors' own creation

$N A$, negative affectivity; $P A$, positive affectivity.

FIGURE 1: The tested measurement model - Confirmatory factor analysis model for the testing of the Positive and Negative Affect Schedule scale as a twodimensional construct in this context.

Post hoc tests were then conducted in order to improve the fit of the model, and also to determine which individual affect items might better, according to the data, be considered direct predictors of student performance in this context. An inspection of the MI indicated the presence of a range of relatively high values for certain regression weights and covariances between error terms. One at a time, paths were freed up. All of these adjustments met the substantive requirements for adjustment (Byrne, 2010). In each case, the model fit statistics were found to improve. One path, from positive affectivity to student performance, was not significant and was deleted.

The final model, shown in Figure 3, shows the paths that were freed up on account of the MI values. This model (chisquared $=402.991 ; d f=159 ; \mathrm{CFI}=0.96 ;$ RMSEA $=0.046$; ECVI $=0.762$ ) was taken to represent an acceptable fit with the data. The model is shown without the coefficients in Figure 3, for the sake of clarity.

In the final model, four paths are significant predictors of student marks: (1) the path between negative affect (the latent variable) and student marks, with an unstandardised parameter value of $-11.008(\mathrm{CI}=-18.854[1] ;-3.510[\mathrm{u}] ; p<$ $0.016)$ and a standardised parameter of $-0.099(\mathrm{CI}=-0.161[1]$; $-0.03[\mathrm{u}] ; p<0.018$ ), (2) the path between determined and student marks, with an unstandardised parameter of -5.756 $(\mathrm{CI}=-7.933[1] ;-3.622[\mathrm{u}] ; p<0.0001)$ and a standardised parameter of $-0.182(\mathrm{CI}=-0.248[1] ;-0.115[\mathrm{u}] ; p<0.0001)$, (3) the path between upset and student marks, with an unstandardised parameter of $-3.298(\mathrm{CI}=-5.743[1]$; $-0.795[\mathrm{u}]$; $p<0.029)$, and a standardised parameter of $-0.083(\mathrm{CI}=$ $-0.145[1] ;-0.02[u] ; p<0.029)$ and (4) the path from active to student marks, with an unstandardised parameter of -2.154 $(\mathrm{CI}=-3.069[1] ;-1.188[\mathrm{u}] ; p<0.0001)$ and a standardised parameter of $-0.147(\mathrm{CI}=-0.208[1] ;-0.081[\mathrm{u}] ; p<0.0001)$.
It is acknowledged that these results cannot indicate causality. Further, it is acknowledged that these results cannot identify which particular causal mechanisms underlie the negative associations between NA and student performance. Nonetheless, it is argued that these results support certain theory that predicts this negative relationship between NA and performance, whether it is based on the potential constraints on student creativity posed by NA (Bledow et al., 2013), the potential constraints posed by NA on proactive behaviour (Parker et al., 2013), potential differences in cognitive processes such as memory processing associated with NA (Storbeck, 2013) or through causal mechanisms related to the influence of NA on stress and the way individuals cope with it (Brief et al., 1988).

The significance of NA as a negative predictor of student performance also supports the arguments of Spektor et al. (2000), who argue that affect, and particularly NA, has a substantive influence on performance relationships.

The literature suggests that PA, through its inverse association with NA (through its shared variance component), might be associated with proactive behaviour that derives from an appetitive or approach system (a BAS) underpinned by motivation related to rewards (Atkinson et al., 2013). To some extent it might be possible that these items, 'determined' and 'active', reflect this particular motivational system structure and its predicted positive association between PA and performance in different contexts.

The negative associations between student performance and both the NA and the 'upset' variable also support Atkinson et al.'s (2013) prediction that NA is typically associated with lower levels of performance in different contexts. Atkinson et al. (2013) predict that NA is associated with behaviours geared towards the avoidance of negative stimulus: a defensive or withdrawal system of motivation (a BIS). This is but one plausible explanation for this relationship.

These results might also support the predicted potential differences in decision-making styles for individuals that may be associated with different endowments of affectivity (Lowe \& Reckers, 2012), or the potential negative influence of NA on perseverance (Vandenberghe et al., 2011) and on physical wellbeing (Denollet, 2005).

Further research is recommended, in order to establish which of these, or other, causal mechanisms may underlie these findings or, indeed, the relative contribution of each of these causal mechanisms to student performance in these and similar contexts.

At this point in the analysis, an EFA was applied. Because the structure of affect in this context did not necessarily reflect a two-dimensional factor structure, the EFA was used to understand how many dimensions might underlie affect in this context. The Kaiser-Meyer-Olkin value for the model was 0.859 (approximate chi-square $=6181.422$ ). The Bartlett sphericity test value was significant $(p<0.0001 ; d f=190)$. 
These measures were taken to suggest the sampling adequacy of the model was acceptable. Table 2 shows the rotated component matrix of the affect variables.

The first component category comprises all the PA variables: interested, excited, mentally strong, enthusiastic, alert, inspired, attentive, active, proud and determined. This factor is categorised as 'Engagement'. This factor is similar to the 'Enthusiastic/Aroused' factor previously identified by Lowe and Reckers (2012), the dominant factor in their principle components analysis of positive affect. In their analysis, this factor, together with another termed 'Happiness' (comprised of the variables happy, pleased, optimistic and content), contributed $61.35 \%$ of the variance.

The second component category is comprised of the variables guilty, afraid, nervous, jittery and scared. This factor is categorised as 'Anxiety'. This factor is similar to the factor 'Fear' found by Lowe and Reckers (2012) to be their second of two factors (in their analysis this factor comprised the negative affect items nervous, afraid, worried and scared).

The third component category comprises the variables upset, distressed, irritable and jittery, with the latter variable shared with factor two. Factor three is therefore termed 'Upset'. Factor four comprises the variables hostile and ashamed, and is named 'Hostility'. This factor bears some resemblance with Lowe and Reckers's (2012) primary factor in their analysis of NA variables, termed 'Frustrated', which comprised the items frustrated, upset, jittery, irritated, unhappy, hostile and angry.

Having investigated the underlying commonalities in the structure of affect in this context, a bivariate analysis of the associations of each of the individual affect items with student performance was applied.

\section{Bivariate results: Positive affect}

Although PA, as a latent variable, was not found to be significantly associated with student performance according to the Spearman Rho bivariate tests, certain of the individual PA items were found to be. As reported above, all the subordinate PA items were found to load on one component

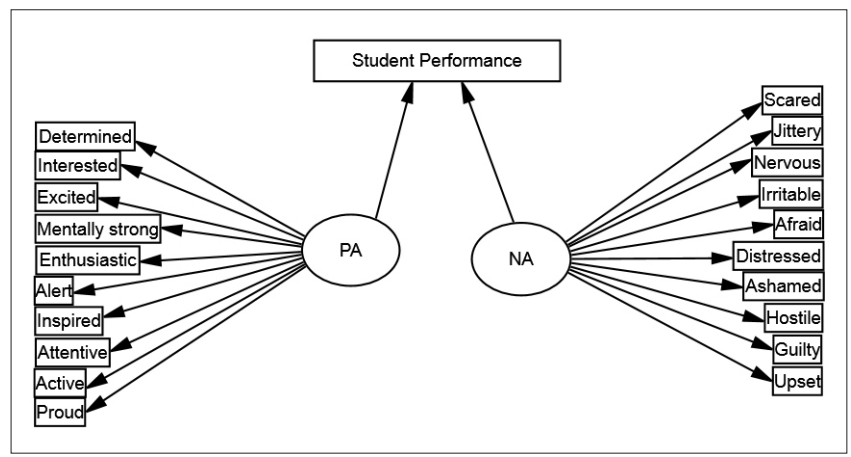

Source: Authors' own creation

$N A$, negative affectivity; PA, positive affectivity.

FIGURE 2: The preliminary tested model with measurement model and structural model components. category. This category was termed 'Engagement'. Of these variables, according to the bivariate tests, the mentally strong variable $(0.089 ; p<0.017)$ and the determined variable $(0.132$; $p<0.0001)$ are each positively and significantly associated with student performance. These results provide support for the notion that engagement might be a dimension along which positive affect items may contribute to student performance. These results support findings that suggest that positive affectivity can influence performance (Bouckenooghe et al., 2013). These results support the notion that PA (or that component of PA that is inversely associated with NA) can be associated with a BAS, or a behavioural activation system, based on rewards or positive stimuli (Atkinson et al., 2013), in that this motivational system is related to proactive engagement with tasks, which might result in higher levels of performance in activities. However, as stressed above, this is but one of the dimensions along which the literature suggests a positive relationship between PA and performance. In contrast to the multivariate testing, the bivariate association for the mentally strong variable is significant rather than the bivariate association for the active variable. Both of these variables, however, fall into the engagement component category identified as the primary factor (component category one) of the EFA. The implication of the change in the significance of the associations of the variables is perhaps that when other relationships in the model are taken into account, the active variable is a more appropriate reflection of the relationship.

In any event, these positive associations specifically support the argument of Bledow et al. (2013): that positive affect can contribute positively to academic performance. Bledow et al. (2013) found that positive affect is positively related to creativity, particularly in student populations. However, as previously indicated, the analysis of the causal mechanisms that underlie these associations are beyond the scope of this work.

The specific relationships between creativity and student performance are beyond the scope of this research, but it is acknowledged that further research might offer more insight into this as a potential causal mechanism that might underpin these net results found here. Lowe and Reckers (2012) found individuals categorised into their 'Enthusiasm/Arousal'

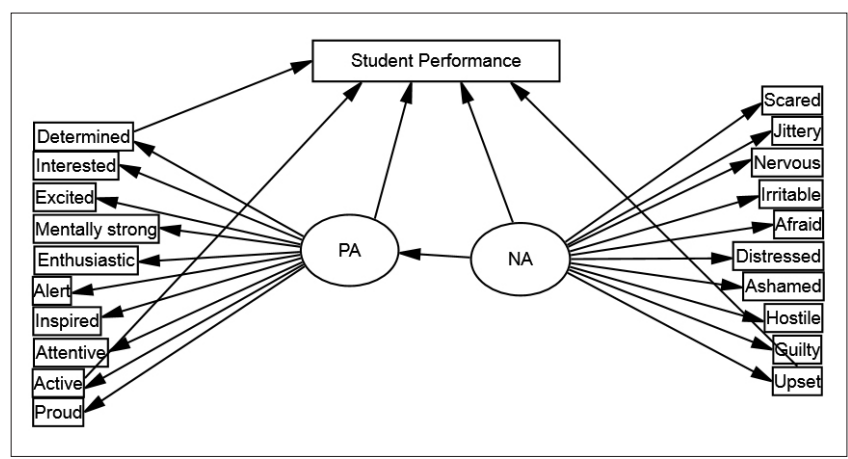

Source: Authors' own creation

NA, negative affectivity; PA, positive affectivity.

FIGURE 3: The final model, showing the model specifically fitted to the data in this context. 
factor were less likely to potentially acquiesce to unethical behaviours. This finding is relevant because it indicates that substantive differences in behavioural intentions, of some sort, have been found to be associated with this factor grouping. Aggregate PA (the average of the PA observed items) is not, however, found to be significantly associated with student performance $(0.046 ; p<0.214)$. This suggests that the relationships between positive affect and student performance might need to be related to more specific affective dimensions. Further qualitative research might better be able to surface the specific causal mechanisms that underlie these findings.

\section{Bivariate results: Negative affect}

Of the category two variables which loaded as the 'Anxiety' factor, according to the Spearman tests, all of the component variables were found to be negatively and significantly associated with student performance: guilty $(-0.118 ; p<$ $0.001)$, afraid $(-0.157 ; p<0.0001)$, nervous $(-0.142 ; p<0.0001)$; jittery $(-0.122 ; p<0.001)$ and scared $(-0.118 ; p<0.001)$. This factor was found to share characteristics with Lowe and Reckers's (2012) 'Fear' factor, which in their research was found to have no relationship to potential acquiescence to unethical practices.

Of the category three variables (the 'Upset' category), the upset variable $(-0.133 ; p<0.0001)$ and the distressed variable $(-0.119 ; p<0.001)$ are negatively and significantly associated with student marks. Lowe and Reckers's (2012) 'Frustrated' factor shares some commonalities with this dimension; in their research individuals in this category were found to be more likely to potentially acquiesce to unethical practices.
Although this previous research does indicate that differences in behaviour between these categories can exist, the causal mechanisms that underlie these differences remain unclear.

At the aggregate level, NA is found to be significantly and negatively associated with student performance. According to Bledow et al. (2013), creativity might be inhibited by NA, although it might have a role in creativity by providing $a$ priori conditions for PA to facilitate increased creativity. It is possible that the potential positive influence of NA on creative performance through its effect of increasing effort investments and reducing complacency (George \& Zhou, 2002) is not a dominant effect in this context. As discussed above, the relationships between creativity and student performance are beyond the scope of this study. However, it is acknowledged that this might be one dimension of the causal structure that underlies these findings.

These results are consistent with other findings that indicate that different behaviours are expected of individuals according to differences in affectivity, which can impact on the performance of tasks (Parker et al., 2013). If higher levels of NA are associated with behaviours that are focused less on proactive approaches to challenges and more on protection, or on the reduction of potential loss (Parker et al., 2013), then it is plausible that student performance might be constrained by NA related to this as another potential causal mechanism.

On the basis of these results, it is argued that affectivity may have an influence on student performance. If the literature has shown that, under experimental conditions, PA can be increased, and NA can be decreased, when tasks are made

TABLE 2: Factor analysis rotated component matrix of the affect variables.

\begin{tabular}{|c|c|c|c|c|c|c|}
\hline Affect items & $\begin{array}{l}\text { Component } 1 \\
\text { (Engagement) }\end{array}$ & $\begin{array}{l}\text { Component } 2 \\
\text { (Anxiety) }\end{array}$ & $\begin{array}{l}\text { Component } 3 \\
\text { (Upset) }\end{array}$ & $\begin{array}{l}\text { Component } 4 \\
\text { (Hostility) }\end{array}$ & $\begin{array}{l}\text { Communalities (h2): } \\
\text { Squared multiple } \\
\text { correlation }\end{array}$ & $\begin{array}{l}\text { Communalities (h2): } \\
\text { Extraction }\end{array}$ \\
\hline Interested & $0.698 \dagger$ & 0.121 & -0.245 & -0.01 & 1 & 0.562 \\
\hline Mentally strong & $0.575 \dagger$ & -0.346 & -0.116 & 0.070 & 1 & 0.469 \\
\hline Enthusiastic & $0.735 \dagger$ & -0.052 & -0.078 & -0.01 & 1 & 0.549 \\
\hline Alert & $0.573 \dagger$ & -0.141 & 0.186 & -0.173 & 1 & 0.416 \\
\hline Attentive & $0.648 \dagger$ & -0.072 & -0.005 & -0.103 & 1 & 0.436 \\
\hline Active & $0.660 \dagger$ & -0.136 & 0.046 & -0.170 & 1 & 0.485 \\
\hline Proud & $0.624 \dagger$ & -0.157 & 0.126 & 0.072 & 1 & 0.435 \\
\hline Upset & -0.120 & 0.263 & 0.702 & 0.078 & 1 & 0.582 \\
\hline Guilty & -0.090 & $0.890 \dagger$ & 0.171 & -0.025 & 1 & 0.830 \\
\hline Hostile & -0.093 & -0.184 & 0.181 & $0.635 \dagger$ & 1 & 0.479 \\
\hline Ashamed & -0.112 & 0.149 & -0.093 & $0.772 \dagger$ & 1 & 0.639 \\
\hline Distressed & 0.056 & 0.207 & $0.633 \dagger$ & -0.045 & 1 & 0.448 \\
\hline Afraid & -0.161 & 0.760 & 0.267 & -0.043 & 1 & 0.677 \\
\hline Irritable & -0.162 & 0.109 & $0.721 \dagger$ & 0.028 & 1 & 0.558 \\
\hline Nervous & -0.060 & 0.713 & 0.280 & 0.075 & 1 & 0.596 \\
\hline Jittery & 0.050 & 0.361 & $0.571 \dagger$ & 0.055 & 1 & 0.462 \\
\hline Scared & -0.087 & $0.897 \dagger$ & 0.188 & -0.028 & 1 & 0.848 \\
\hline Total variance explained & 5.290 & 3.304 & 1.355 & 1.058 & - & - \\
\hline Percentage of variance explained & $26.45 \%$ & $16.52 \%$ & $6.774 \%$ & $5.292 \%$ & - & - \\
\hline Cumulative percentage of variance explained & $26.45 \%$ & $42.97 \%$ & $49.75 \%$ & $55.039 \%$ & - & - \\
\hline
\end{tabular}

$\dagger$, Show the loadings that are used to identify the component categories, that are above the cutoff value applied $(0.40)$. 
to be more meaningful (Schutte et al., 2012), then it is argued that further research should investigate the extent to which students can be affectively supported. If creativity can be managed through affective support given to students (Bledow et al., 2013), then attempts should be made to support and empower students to increase their performance; support given to tertiary-level students should also take the form of emotional and affectivity support.

\section{Limitations and recommendations}

A limitation of this research is that it offers a cross-sectional perspective of the associations of affect, at a point in time. Further longitudinal research is recommended, in order to verify if these effects persist over time. The Harmon test indicates no evidence of common method bias. However, a major limitation of this research is that it uses quantitative methods, which cannot ascribe causality. Further research is recommended, that builds on these findings by exploring the causal mechanisms that might underlie these results.

Further research is recommended into the potential influence of NA and PA on creativity, and the further influence of creativity on student performance in this context. Such research might offer more insight into this as a causal structure suggested by Bledow et al. (2013). If NA and PA are mutually inhibitory (Bledow et al., 2013) then this might have implications for student performance.

According to Bledow et al. (2013), although creativity is related to affect, studies also need to take into account the wider spectrum of affect, including anxiety, frustration and distress. Qualitative research might offer causal insights that are beyond the capability of empirical work.

Affect regulation can be used 'as potential leverage for increasing creativity and innovation' (Bledow et al., 2013, p. 446). Further research might also offer insights into how practical measures can be used to support affect regulation.

If students with higher NA might be more concerned with loss aversion than proactive approaches to problem solving (Parker et al., 2013) then it might be necessary to provide affective support for students. Encouraging students to be part of extracurricular activities that are designed to provide a positive climate of support may be particularly important in this context for first-year students.

In experimental conditions, PA has been shown to increase, and NA to decrease, when tasks are more meaningful (Schutte et al., 2012). The implication of this past research is that affectivity can be managed (Schutte et al., 2012). Lecturers at this level should perhaps attempt to increase the meaningfulness of learning activities, however this might be enabled.

According to the seminal NA literature, there are certain causal mechanisms that might underlie the way NA may constrain performance (Spektor et al., 2000). It is recommended that student advisors be appointed amongst the staff of higher educational institutions in this context, with a specific focus on supporting first-year students. Based on Spektor et al.'s (2000) proposed causal mechanisms, it is suggested that students be supported and encouraged to frame learning tasks in a positive way, that their levels of anxiety are reduced through engagement and support and that learning tasks are well articulated and supported so that contextual experiences do not influence levels of NA themselves.

\section{Conclusion}

This research sought to (1) investigate the factor structure of affectivity in the context of South African higher education and to (2) investigate the potential relationships between student performance and the affectivity dimension of positive and negative affectivity.

On the basis of a CFA and, subsequently, an EFA, it was concluded that affectivity does not necessarily reflect a twodimensional construct, but might better be represented by a model with more than two dimensions in this context.

SEM analysis suggested that the latent variable NA is a negative predictor of student performance, together with one subordinate NA item. The latent variable PA was not found to be significantly associated with student performance but two of its subordinate items were.

Subordinate affectivity items that comprised component categories derived from the EFA were found to be significantly associated with student performance. All the PA items loaded on the primary component category, termed 'Engagement', and two of these items were found to be positively associated with student performance. The NA items loaded onto three component categories, termed 'Anxiety', 'Upset' and 'Hostility'.

According to bivariate testes, all of the subordinate NA items that loaded on the 'Anxiety' component category were found to be negatively associated with student performance. Of the 'Upset' category, two variables were found to be negatively associated with student performance.

On the basis of these results, it was concluded that different bodies of theory that predicted a negative association between NA and student performance and a positive association between PA and student performance were supported. Despite a range of predicted mechanisms that might underpin these results, it is acknowledged that this study does not offer a specific test of these specific mechanisms. However, on the basis of these findings, it is argued that students may benefit from support interventions to reduce their anxiety and other dimensions of NA and to encourage the meaningfulness of their experience, which might improve levels of PA in this cohort of students, particularly in their first year of studies.

\section{Acknowledgements Competing interests}

The authors declare that they have no financial or personal relationship(s) that may have inappropriately influenced them in writing this article. 


\section{Authors' contributions}

C.W.C. (University of the Witwatersrand) was responsible for the conceptualisation of the article, the development of the research design and the statistical analysis. E.P. (University of the Witwatersrand) was also responsible for the intellectual conceptualisation and development of the article and ran the project from its start to its completion, including the processes related to data collection and administration. On balance, each author contributed about half of the work involved in this project.

\section{References}

Amabile, T.M., Barsade, S.G., Mueller, J.S., \& Staw, B.M. (2005). Affect and creativity at work. Administrative Science Quarterly, 50, 367-403. http://dx.doi.org/10.2189/ asqu.2005.50.3.367

Atkinson, J., Sharp, C., Schmitz, J., \& Yaroslavsky, I. (2013). Behavioral activation and inhibition, negative affect, and gambling severity in a sample of young adult college students. Journal of Gambling Studies, 28, 437-449. http://dx.doi. org/10.1007/s10899-011-9273-x

Bledow, R., Rosing, K., \& Frese, M. (2013). A dynamic perspective on affect and creativity. Academy of Management Journal, 56(2), 432-450. http://dx.doi. org/10.5465/amj.2010.0894

Bouckenooghe, D., Raja, U., \& Butt, A.N. (2013). Combined effects of positive and negative affectivity and job satisfaction on job performance and turnover
intentions. Journal of Psychology, 147(2), 105-123. http://dx.doi.org/10.1080/0 intentions. Journal of
0223980.2012 .678411

Bowling, N.A., Hendricks, E.A., \& Wagner, S.H. (2008). Positive and negative affectivity and facet satisfaction: A meta-analysis. Journal of Business \& Psychology, 23, 115125. http://dx.doi.org/10.1007/s10869-008-9082-0

Brief, A.P., Burke, M.J., George, J.M., Robinson, B.S., \& Webster, J. (1988). Should negative affectivity remain an unmeasured variable in the study of job stress? Journal of Applied Psychology, 73(2), 193-198. http://dx.doi.org/10.1037/00219010.73.2.193

Byrne, B.M. (2010). Structural equation modeling with AMOS. New York, NY: Taylor and Francis.

Chen, C., Chen, M.Y., \& Liu, Y. (2013). Negative affectivity and workplace deviance: The moderating role of ethical climate. International Journal of Human Resource Management, 24(15), 2894-2910. http://dx.doi.org/10.1080/09585192.2012.75 3550

Crawford, J.R., \& Henry, J.D. (2004). The positive and negative affect schedule (PANAS): Construct validity, measurement properties, and normative data in large clinical sample. British Journal of Clinical Psychology, 43, 245-265. http:// dx.doi.org/10.1348/0144665031752934

Cresswell, J.W. (2003). Research design. Qualitative, quantitative and mixed methods approaches. (2nd edn.). Thousand Oaks, CA: Sage.

Denollet, J. (2005). DS14: Standard assessment of negative affectivity, social inhibition, and type D personality. Psychosomatic Medicine, 67, 89-97. http:// dx.doi.org/10.1097/01.psy.0000149256.81953.49

Ebesutani, C., Okamura, K., Higa-McMillan, C., \& Chorpita, B.F. (2011). A psychomeric analysis of the positive and negative affect schedule for children-parent version in a school sample. Psychological Assessment, 23(2), 406-416. http://dx.doi. org/10.1037/a0022057

Franklin, J.C., Lee, K.M., Hanna, E.K., \& Prinstein, M.J. (2013). Feeling worse to feel better: Pain-offset relief simultaneously stimulates positive affect and reduces negative affect. Psychological Science, 24(4), 521-529. http://dx.doi. org/10.1177/0956797612458805

George, J.M., \& Zhou, J. (2002). Understanding when bad moods foster creativity and good ones don't: The role of context and clarity of feelings. Journal of Applied Psychology, 87(4), 687-697. http://dx.doi.org/10.1037/0021-9010.87.4.687

Gilmore, P.L., Hu, X., Wei, F., Tetrick, L.E., \& Zaccaro, S.J. (2013). Positive affectivity neutralizes transformational leadership's influence on creative performance and organisational citizenship behaviours. Journal of Organizational Behavior, 34(8), 1061-1075. http://dx.doi.org/10.1002/job.1833

Hair, J.F., Black, W.C., Babin, B.J., \& Anderson, R.E. (2010). Multivariate data analysis. A global perspective. (7th edn.). New Jersey: Pearson Education.
Jain, A.K., Malhotra, N.K., \& Guan, C. (2012). Positive and negative affectivity as mediators of volunteerism and service-oriented citizenship behavior and mediators of volunteerism and service-oriented citizenship behavior and customer loyalty. Psycholog

Lonigan, C.J., Hooe, E.S., David, C.F., \& Kistner, J.A. (1999). Positive and negative affectivity in children: Confirmatory factor analysis of a two-factor model and its relation to symptoms of anxiety and depression. Journal of Consulting and Clinical Psychology, 67(3), 374-386. http://dx.doi.org/10.1037/0022-006X.67.3.374

Lowe, D.J., \& Reckers, P.M.J. (2012). An examination of the contribution of dispositional affect on ethical lapses. Journal of Business Ethics, 111, 179-193. http://dx.doi. org/10.1007/s10551-011-1200-7

Lucas, T. (2009). Justifying outcomes versus processes: Distributive and procedura justice beliefs as predictors of positive and negative affectivity. Current Psychology, 28, 249-265. http://dx.doi.org/10.1007/s12144-009-9066-x

Luo, P., \& Bao, Z. (2013). Affectivity, emotional exhaustion, and service sabotage behaviour: The mediation role of rumination. Social Behavior \& Personality: An International Journal, 41(4), 651-661. http://dx.doi.org/10.2224/ sbp.2013.41.4.651

Moyle, P. (1995). The role of negative affectivity in the stress process: Tests of alternative models: Summary. Journal of Organizational Behavior, 16(6), 647-668. http://dx.doi.org/10.1002/job.4030160705

O'Brien, A., Terry, D.J., \& Jimmieson, N.L. (2008). Negative affectivity and responses to work stressors: An experimental study. Anxiety, Stress, \& Coping, 21(1), 55-83. http://dx.doi.org/10.1080/10615800701529504

Parker, S.K., Johnson, A., Collins, C., \& Nguyen, H. (2013). Making the most of structural support: Moderating influence of employees' clarity and negative affect. Academy of Management Journal, 56(3), 867-892. http://dx.doi.org/10.5465/ Academy of $M$ and
amj.2010.0927

Podsakoff, P.M., MacKenzie, S.B., Lee, J.Y., \& Podsakoff, N.P. (2003). Common method biases in behavioural research: A critical review of the literature and recommended remedies. Journal of Applied Psychology, 88, 879-903. http:// recommended remedies. Journal of Applie
dx.doi.org/10.1037/0021-9010.88.5.879

Ruedy, N.E., Moore, C., Gino, F., \& Schweitzer, M.E. (2013). The cheater's high: The unexpected affective benefits of unethical behaviour. Journal of Personality and Social Psychology, 105(4), 531-548. http://dx.doi.org/10.1037/a0034231

Schutte, N.S., Searle, T., Meade, S., \& Dark, N.A. (2012). The effect of meaningfulness and integrative processing in expressive writing on positive and negative affect and life satisfaction. Cognition and Emotion, 26(1), 144-152. http://dx.doi.org/10 $.1080 / 02699931.2011 .562881$

Shallcross, A., Ford, B.Q., Floerke, V.A., \& Mauss, I.B. (2013). Getting better with age: The relationship between age, acceptance, and negative affect. Journal of Personality and Social Psychology, 104(4), 734-749. http://dx.doi.org/10.1037/ a0031180

Spektor, P.E., Zapf, D., Chen, P.Y., \& Frese, M. (2000). Why negative affectivity should not be controlled in job stress research: Don't throw out the baby with the bath water. Journal of Organizational Behavior, 21, 79-95. http://dx.doi.org/10.1002/ (SICI)1099-1379(200002)21:1<79::AID-JOB964>3.0.CO;2-G

Storbeck, J. (2013). Negative affect promotes encoding of and memory for details at the expense of the gist: Affect, encoding and false memories. Cognition \& Emotion, 27(5), 800-819. http://dx.doi.org/10.1080/02699931.2012.741060

Vandenberghe, C., Panaccio, A., \& Ayed, A.K.B. (2011). Continuance commitment and turnover: Examining the moderating role of negative affectivity and risk aversion. Journal of Occupational and Organizational Psychology, 84, 403-424. http:// dx.doi.org/10.1348/096317910X491848

Walker, D.D., Van Jaarsveld, D.D., \& Skarlicki, D.P. (2014). Exploring the effects of individual customer incivility encounters on employee incivility: The moderating roles of entity (in)civility and negative affectivity. Journal
Psychology, 99(1), 151-161. http://dx.doi.org/10.1037/a0034350

Watson, D., \& Clark, L.A. (1984). Negative affectivity: The disposition to experience aversive emotional states. Psychological Bulletin, 96, 465-490. http://dx.doi. org/10.1037/0033-2909.96.3.465

Watson, D., Clark, L.A., \& Tellegen, A. (1988). Development and validation of brief measures of positive and negative affect: The PANAS scales. Journal of Personality and Social Psychology, 54(6), 1063-1070. http://dx.doi.org/10.1037/00223514.54.6.1063

Wegge, J., Van Dick, R., \& Von Bernstorff, C. (2010). Emotional dissonance in call centre work. Journal of Managerial Psychology, 25(6), 596-619. http://dx.doi. org/10.1108/02683941011056950

Williams, L., Gavin, M.B., \& Williams, M.L. (1996). Measurement and nonmeasurement processes with negative affectivity and employee attitudes. Journal of Applied Psychology, 81(1), 88-101. http://dx.doi.org/10.1037/0021-9010.81.1.88

World Economic Forum. (2012). The Global Competitiveness Report. Retrieved January 30, 2013, from http://www3.weforum.org/docs/WEF GlobalCompetitivenessReport_2012-13.pdf 